\title{
REVIEW
}

\section{Telomere dynamics: the means to an end}

\author{
M. Matulić, M. Sopta and I. Rubelj \\ Ruđer Bošković Institute, Department of Molecular Biology, Zagreb, Croatia
}

Received 16 November 2006; revision accepted 28 February 2007

\begin{abstract}
Telomeres are among the most important structures in eukaryotic cells. Creating the physical ends of linear chromosomes, they play a crucial role in maintaining genome stability, control of cell division, cell growth and senescence. In vertebrates, telomeres consist of G-rich repetitive DNA sequences (TTAGGG)n and specific proteins, creating a specialized structure called the telosome that through mutual interactions with many other factors in the cell give rise to dynamic regulation of chromosome maintenance. In this review, we survey the structural and mechanistic aspects of telomere length regulation and how these processes lead to alterations in normal and immortal cell growth.
\end{abstract}

Telomeres are specialized structures found at the ends of linear chromosomes, and over the last decade an increasing body of information has been gathered to create a more complete picture of how telomeres are organized and regulated. Telomeres and telomerase, a reverse transcriptase that extends telomeres, are key players in the initiation of immortalization, as well as the maintenance of the immortal state of cancer cells. Although immortalization of normal cells by spontaneous activation of endogenous telomerase is extremely rare, normal mortal cells may become growth deregulated through mutations of cell cycle control genes such as p53, pRB, p21, p16 and others (Vaziri \& Benchimol 1996). Such transformed cells undergo extended lifespan and extreme genome instability in crisis, characterized by massive cell death, through which some of them may become immortal by activation of endogenous telomerase (Hackett \& Greider 2002) or through rare activation of alternative recombination-based mechanisms of telomere maintenance (ALT) (Bryan et al. 1995). Therefore, knowledge of the molecular structure and function of telomeres, including telomere proteins and their mutual interactions will contribute to our understanding of the processes of cell immortalization and cancer.

\section{TELOMERIC STRUCTURE}

Nearly 60 years ago, the first experiments identified specific structures important for genome stability, at the ends of Drosophila and maize chromosomes. These protective chromosome ends, 


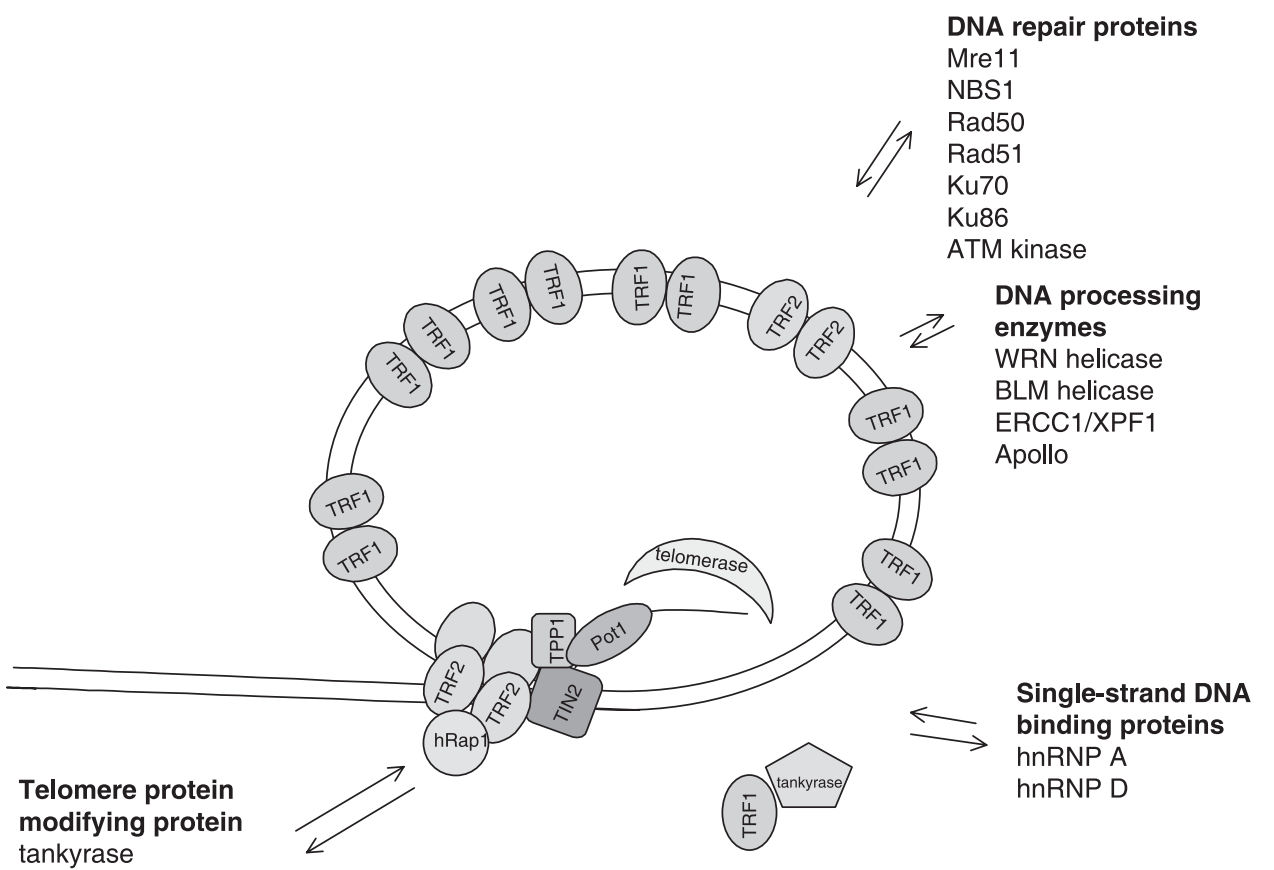

Figure 1. Telomeres are complex and dynamic structures. The core telomere complex consists of six telomeric DNA binding proteins that interact dynamically with various other protein factors, including DNA repair proteins, DNA processing enzymes, single-stranded DNA binding proteins and in human cells, tankyrase. Tankyrase modifies TRF1 releasing it from telomeric DNA; this contributes to conformational change in the telomeric structure, promotes telomerase access to the $3^{\prime}$-single-stranded telomere end.

named telomeres (for review, see Wai 2004) are composed of specialized DNA/protein complexes. Early analysis of telomeric heterochromatin showed that linear chromosomes end with short tandem repeats consisting of guanine-rich sequences, such as TTAGGG in vertebrates (de Lange et al. 1990). Telomeres are dynamic structures and their length varies among organisms or cells of different origin. For example, mice can have telomeres up to $150 \mathrm{~kb}$ long, while in humans the length can vary from 3 to $20 \mathrm{~kb}$ (Moyzis et al. 1988; Harley et al. 1990). Electron microscope studies revealed a specific telomere structure in the form of a telomere loop (t-loop) or lariat (Griffith et al. 1999; Rubelj \& Vondracek 1999). Each telomere ends with a G-rich 3'single-stranded overhang, at least $12 \mathrm{bp}$ long, which is found in homologous double-stranded telomeric DNA forming a local D-loop (displacement loop) that stabilizes the lariat telomeric structure (Greider 1999, Fig. 1). Because invasion of a 3'-single-stranded overhang takes place at the telomere border region, the radius of the t-loop depends on telomere length. In vivo C-rich $5^{\prime}$ strands end with exactly the same bases (CCAATC- $5^{\prime}$ ), which indicates modulation by special enzymes (Sfeir et al. 2005). These facts implicate the importance of the telomere sequence for the whole DNA-protein superstructure. The whole t-loop entity is held together by several telomere-specific proteins, as well as a number of other ubiquitous proteins involved in DNA processing and structure organization (de Lange 2005). The subtelomeric region adjacent to the t-loop is heterochromatic and contains repetitive, as well as corrupted telomeric sequences and can stretch up to 10-500 kb towards the centromere (Riethman et al. 2005). Special histone and DNA modifications (such as acetylation and methylation) in subtelomeric and telomeric 
regions can regulate chromatin structure or processes that include replication and homologous recombination (Gonzalo et al. 2006).

In normal cells, telomeres shorten with each round of replication, due to the inability of DNA polymerase to synthesize the very end of the DNA lagging strand, as well as due to the presence of $5^{\prime}$ exonuclease activity (Makarov et al. 1997). It is estimated that each passage through the cell cycle leads to shortening of telomeres by 50-150 bp (Olovnikov 1973; Makarov et al. 1997). Telomere erosion is considered to be a mitotic clock, which regulates the number of divisions before cells enter senescence. In addition to gradual telomere shortening, certain unrepaired DNA damage and epigenetic factors can also contribute to abrupt telomere shortening and sudden and stochastic cell senescence (Smith \& Whitney 1980; Rubelj \& Vondracek 1999).

As part of the chromosome, telomeres contain histones forming nucleosomes, chromosome structural proteins (Nikitina \& Woodcock 2004) and some specific single-stranded DNA binding proteins with a great affinity for single-stranded telomeric sequences (hnRNP A, hnRNP D) (Bandiera et al. 2005; Moran-Jones et al. 2005). Proteins involved in DNA synthesis, such as helicases and endonucleases are present at the telomere, as well as telomerase, a reverse transcriptase complex involving an hTR RNA component and the hTERT protein catalytic subunit, present in telomerase positive-cells. Telomeres also interact with modulators of specific telomere proteins, which allow access of telomerase, and a number of other proteins involved in damage recognition and repair by homologous/non-homologous recombination (reviewed in de Lange 2005).

\section{TELOMERE DNA BINDING PROTEINS}

Six proteins are considered to be strictly telomere specific. As suggested by de Lange (2005), they meet the following criteria; they are specific for telomere DNA, present throughout the cell cycle and have functions restricted to the telomere. They have important roles in protection, elongation and regulation of the telomere. These proteins form a complex named shelterin: TRF1, TRF2, hRap, TIN2, POT1 and TPP (TINT/PTOP/PIP) (Zhong et al. 1992; Bilaud et al. 1997; Broccoli et al. 1997; Bianchi \& de Lange 1999; Kim et al. 1999; Li et al. 2000; Loayza \& de Lange 2003; Houghtaling et al. 2004; Liu et al. 2004a,b; Ye \& de Lange 2004a; de Lange 2005). Some of these proteins have been characterized as specific telomere sequence-binding proteins, while others were detected in complex with them by gel filtration and mass spectrometry. The whole telomere superstructure seems to be dynamic, switching between an 'open' conformation that allows telomerase to dock onto the telomere and a 'closed' conformation that protects telomeres from telomerase, nucleases or polymerases (Rubelj \& Vondracek 1999; Karlseder et al. 2002; Colgin \& Reddel 2004; Ferenac et al. 2005; Hockemeyer et al. 2005; Lei et al. 2005). Each protein has a specific role in the complex; such as inducing t-loop formation, protecting the telomere from nucleases, checkpoint functions or regulating telomere elongation in telomerase-positive cells (Fig. 1).

TRF1 (telomere repeat binding factor 1) was one of the first proteins identified at telomere sites (Zhong et al. 1992). It is expressed continuously throughout the cell cycle, and it binds exclusively to telomeric TTAGGG repeats. TRF1 homodimers can bind, not only neighbouring telomeric sequences, but can also bridge two different DNA molecules or distant regions of the same telomere (Griffith et al. 1998; Bianchi \& de Lange 1999). TRF1 seems to be the main telomerebinding protein. It binds to telomere DNA as a dimer and probably makes higher-order structures by synaptic pairing with dimers of parallel telomere strands (Bianchi et al. 1997; Griffith et al. 
1998). In addition, a tankyrase-binding motif has being discovered (lacking in mouse TRF1) that is possibly responsible for the regulation of telomere elongation by telomerase (Sbodio \& Chi 2002); the amount of TRF1 on telomeres corresponds to the telomere length (Smogorzewska et al. 2000). Functional experiments defined this protein as the main regulator of telomere elongation by telomerase. A dominant negative mutant of TRF1 causes telomere elongation in telomerase-positive cells, while TRF1 overexpression causes gradual shortening of telomeres until a new length setting is achieved. Thus, TRF1 is considered to be a negative regulator of telomere length. In telomerase-negative cells, changes in TRF1 levels do not change the rate of telomere shortening, indicating a role for TRF1 in control of telomere elongation by telomerase (Karlseder et al. 2002; Karlseder et al. 2003).

TRF2 (telomere repeat binding factor 2) is another telomere repeat binding protein, which shares many characteristics with TRF1. Both proteins are expressed throughout the cell cycle and specifically bind telomere sequences. They share some structural similarities, such as domains for dimerization and DNA binding Myb-like motifs. In addition, they both form homodimers and bind DNA through their Myb-like domain. Due to specific binding regions, which differ in each protein, they can not form mutual heterodimers. TRF2 binds DNA four times more weakly than TRF1, due to differences in amino acids responsible for contact with the minor grove of DNA (Hanaoka et al. 2005). Structural differences between TRF1 and TRF2 are considered responsible for their different functions on the telomere. While TRF1 is mainly involved in telomere length control, TRF2 is involved in telomere protection (van Steensel et al. 1998; Blasco 2005). TRF2 stabilizes the G-rich strand overhang and inhibits telomere-telomere fusions; in addition, TRF2 promotes telomere looping. Griffith et al. (1999) have demonstrated that TRF2 can remodel linear telomeric DNA into large duplex loops in vitro. TRF2 is considered responsible for loop structure in formation of a tetramer at the loop root (Stansel et al. 2001). Although TRF2-mediated DNA looping does not depend on the end structure, a 3'-single-stranded telomeric sequence of at least six nucleotides stabilizes the loop (Yoshimura et al. 2004). In overexpression experiments, TRF2 acts as a negative telomere regulator, causing telomere shortening. Inhibition of TRF2 or expression of a dominant negative mutant causes apoptosis to occur and non-homologous end-joining of telomeres. TRF2 was also found at sites of double-stranded breaks at non-telomeric chromosomal locations (Bradshaw et al. 2005). In such conditions, it was transiently phosphorylated (Tanaka et al. 2005) and its mRNA expression was transiently increased (Klapper et al. 2003). These data indicated a possible role for TRF2 in DNA damage response (Bradshaw et al. 2005). The most unusual characteristic of TRF2 is its ability to delay senescence when overexpressed and to reduce the senescence setpoint or critical telomere length at which normal cells stop dividing (Karlseder et al. 2002).

hRap1 (repressor/activator protein) is a telomere specific protein that acts as a negative regulator of telomere length, although the mechanism by which it does so is still largely unknown. hRap1 is the human homologue of yeast protein scRap1p (Longtine et al. 1989), which is the main telomere DNA binding protein (Li et al. 2000; Hanaoka et al. 2001). In higher eukaryotes, changes in the charge of amino acids in the Myb-like domain, disables hRap1 binding to DNA. As a consequence, hRap1 is connected to the telomere complex through protein-protein interaction with TRF2 (Li et al. 2000; Li \& de Lange 2003; O'Connor et al. 2004). hRap1 has been isolated in complex with TRF2 and proteins involved in homologous and in non-homologous recombination ( $\operatorname{Rad} 50, \mathrm{Mre} 11, \mathrm{Ku} 70 / 86$ and PARP), which could be linked to hRap1 via TRF2 (O’Connor et al. 2004).

TIN2 (TRF1-interacting nuclear factor 2) is one of the most interesting components of the telomeric complex. Its role may be one of providing a scaffold for the binding of other telomeric proteins. TIN2 can simultaneously bind TRF1 and TRF2 in vitro. TIN2 is an essential mediator 
of TRF1 functions, acting as a negative regulator of telomere length. Mutant TIN2 lacking the $\mathrm{N}$-terminal sequence has caused telomere elongation in telomerase-positive cells (Ye et al. 2004b). Transient inhibition of TIN2 led to weakening of telomeric TRF1 signals and TIN2 was found to be a modulator of TRF1 complex ADP-ribosylation (Ye et al. 2004c). Another TIN2 interaction is with TPP1 (PIP/PTOP/TINT) that links the TRF1-TIN2-TRF2 complex with POT1 (Liu et al. 2004b). These connections give TIN2 a central role in keeping telomeric proteins together: it would connect TRF1 with TRF2 and stabilize TRF2 on telomeres, as well as tether TPP1 to TRF1 and TRF2 (Houghtaling et al. 2004). Removal of TIN2 or TRF1 from telomeres leads to TRF2 and Rap1 loss (Ye et al. 2004b).

POT1 (protection of telomeres 1) specifically binds to single-stranded telomere overhangs (Lei et al. 2003). Its function includes telomere protection and regulation of telomere elongation. POT1 is considered to be a chromosome end-capping protein. Loss of the G-overhang causes a reduction in POT1 binding (Ye \& de Lange 2004a). Overexpression of POT1 causes rapid telomere elongation by telomerase, and its loss leads to telomere instability and end fusions (Loayza \& de Lange 2003; Veldman et al. 2004). Lei et al. (2005) analysed its interactions with telomerase in vitro and found that, depending on its location on the single-stranded overhang, relative to the DNA $3^{\prime}$ end, it could facilitate or inhibit telomerase activity. POT1 was defined as a 'switch' between the two telomere states in which telomerase action is allowed or repressed depending on telomere conformation (Ferenac et al. 2005; Hockemeyer et al. 2005; Kelleher et al. 2005; Lei et al. 2005). A third factor would regulate these two states in vivo. POT1 deficiency initiates DNA damage checkpoint activation and aberrant homologous recombination at the telomere, and it is supposed that its role is suppression of the telomere DNA damage response (Churikov et al. 2006; Wu et al. 2006). Additional regulating elements could be differences in POT1 splice variants (Baumann et al. 2002), which are found only in mice.

TPP1 (PIP1/PTOP/TINT1) is a POT1 interacting protein previously identified by several groups and given different names (Houghtaling et al. 2004; Liu et al. 2004a,b; Ye \& de Lange 2004a). It was the 'missing link' that helps keep all six proteins together, recruiting POT1 to the TIN2/TRF1 complex (Ye \& de Lange 2004a). TPP1 structure reveals two protein-protein interacting domains, a central region that has affinity for POT1, and the $\mathrm{C}$ terminus for TIN2 binding. TPP1 acts as negative regulator of telomere length, as its depletion causes telomere elongation (Liu et al. 2004b; Ye \& de Lange 2004a).

Thus, these six telomeric proteins play an important role in telomere protection on the one hand, while on the other hand, in telomerase-positive cells, they regulate telomerase access to telomeric single-stranded overhangs to allow telomere elongation (such as hRap, POT1, TTP1, TIN2) (Loayza \& de Lange 2003; O’Connor et al. 2004; Seimiya et al. 2004). Different mutations (or the absence of) of one of these proteins (such as POT1, TIN2 or TRF1) would change their compact structure, loosen their connections and allow telomerase activity, probably involving other regulatory proteins (such as tankyrase). Abolishing further proteins or functions in the same complex (such as TRF2) would remove protection from telomeres and lead to end-to-end fusions, apoptotic cell death or senescence (van Steensel \& de Lange 1997; Loayza \& de Lange 2003; Veldman et al. 2004; Ye et al. 2004b; de Lange 2005).

\section{TELOMERES AND THE CELL CYCLE}

What happens to the telomere during DNA replication in somatic cells is still unknown. Telomere protein-DNA structure should dynamically change in coordination with the cell cycle, 
to allow access to the replication machinery. Although by immunostaining, all six specific proteins present on the human telomere have been detected during the whole cell cycle, different modifications and changes in their quantity were observed (Shen et al. 1997; Mattern et al. 2004). Functional experiments have shown that activity of some of the telomeric proteins could inhibit cell replication.

TRF1 is considered to be the protein responsible for 'closed' telomeric structure. PIN2, an abundant splice variant of TRF1, which can form homodimers as well as heterodimers with TRF1, has shown cell cycle-dependent changes in quantity, increasing at the $\mathrm{G}_{2} / \mathrm{M}$ border and decreasing in $\mathrm{G}_{1}$ (Shen et al. 1997). PIN2 interacts with the mitotic kinase NIMA indicating interaction with microtubules (Nakamura et al. 2001). Mouse TRF1 has been found on mitotic microtubules, interacting with the spindle checkpoint proteins Mad2 and mitotic kinase Nek2 (Prime \& Markie 2005). In Xenopus, TRF1 has been found located at telomeres only in mitosis and XTRF1 was regulated by Polo-like kinase phosphorylation (Nishiyama et al. 2006). Certain domains responsible for interactions with other proteins are unique to humans, chicken or mouse, indicating different TRF1 regulation (Sbodio \& Chi 2002; Nishiyama et al. 2006). Although found on human telomeres during the whole cycle, TRF1, TRF2 and POT1 appeared to be highly dynamic with different residence times and quantitative changes that could be the consequence of partial release in certain cell cycle phases (Mattern et al. 2004; Wei \& Price 2004; Zhang et al. 2004; Verdun et al. 2005).

These data are in concordance with in vitro functional experiments that show that telomerebound TRF1 and TRF2 significantly stall replication fork progression and inhibit DNA polymerase $\alpha$ at telomeric repeats (Smucker \& Turchi 2001; Ohki \& Ishikawa 2004). Tankyrase expression has been found to strip a fraction of TRF1 off the telomere (Smith et al. 1998).

DNA replication on telomeres is facilitated by the action of helicases, such as WRN and its relative BLM. These $3^{\prime}$ to $5^{\prime}$ helicases can unwind different DNA substrates, such as Holliday structures or G quadruplexes and alternative DNA structures during recombination (in ALT cells) and replication at telomeric ends. They also have $3^{\prime}$ to $5^{\prime}$ exonuclease function (Huang et al. 1998). In cooperation with telomeric proteins (POT1, TRF1 and TRF2), these helicases unwind telomeres but at the same time they inhibit WRN and BLM exonuclease activity, in order to protect the telomeric 3' tail (Lillard-Wetherell et al. 2004; Opresko et al. 2004; Opresko et al. 2005). Werner syndrome patients (lacking WRN) have accelerated telomere erosion and different length dynamics (Schulz et al. 1996; Tahara et al. 1997).

Interactions between telomeres and specific cell structural proteins also influence accessibility of the telomere (Fig. 1). TRF1 is considered to be responsible for protein-protein contacts of inter-phase chromosomes with the nuclear envelope (Luderus et al. 1996). Human heterochromatin protein 1, a nuclear matrix protein, associates with telomeric DNA (Sharma et al. 2003). Kaminker et al. (2005) found TIN2 to have different higher-order nuclear organization in cycling and arrested cells, indicating its role in the control of cell proliferation.

\section{TELOMERE LENGTH REGULATION}

Normal somatic cells cannot elongate their telomeres and they shorten with each division. Finally, they reach a critical length when the cell stops dividing and starts to become senescent. A number of changes in gene expression and chromatin structure accompany this process (Shelton et al. 1999). A cell is disabled from undergoing further divisions as damaged chromosome ends lead to chromosome instability, end fusions and carcinogenetic properties (Bailey \& 
Murnane 2006). In normal somatic cells, telomeric proteins have a role in end protection. Immortal cells, including germ and cancer cells, exhibit telomerase activity; it catalyses de novo synthesis of telomeric repeats at chromosome ends and elongates telomeres (Greider \& Blackburn 1985; Kim et al. 1994). Small quantities of telomerase can also exist in mortal cells in S phase and play a protective role for telomeres (Masutomi et al. 2003). In this context, telomeric proteins take part in the regulation of telomerase access to the telomeres. Additionally, telomerase can be regulated by post-translational modifications, alternative splicing and subcellular localization (Seimiya et al. 2000).

In telomerase-positive cells, telomerase access to telomeres is coordinated with cell cycle progression and telomere protein complex structure. It is supposed that telomerase elongates DNA in the S phase (Masutomi et al. 2003). During the cell cycle, just a few of the shortest telomeres are presumed to be elongated as they may have a more open structure that increases accessibility of telomerase (Teixeira et al. 2004). Regulation of accessibility of the telomeric Goverhang to telomerase is probably dependent on the phase of the cell cycle and telomere length. It also depends on the number and conformation of telomeric proteins; a greater number of TRF1 molecules, in proportion to telomere length, could lead to stronger connections, more compact telomere structure and decreased access of telomerase (de Lange 2005, Fig. 1).

The TRF1 modulating enzyme, tankyrase, releases TRF1 from telomeres and allows access to telomerase. Tankyrase-1 has PARP activity and catalyses the poly(ADP-ribosyl)ation of substrate proteins (Smith et al. 1998). Poly ADP-ribosylated TRF1 has diminished affinity for telomeric DNA, thus telomerase is able to access the telomere and to elongate it (Smith et al. 1998; Smith \& de Lange 2000; Seimiya \& Smith 2002). Overexpression of wild-type human tankyrase 1 induces telomere elongation, but mutated tankyrase does not produce this effect; human but not murine TRF1 has a tankyrase-binding motif (Sbodio \& Chi 2002; Chiang et al. 2006; Hsiao et al. 2006). TRF1 released from telomeres is ubiquitinated and may be quickly degraded in the proteasome, in order to prevent its rebinding to telomere DNA (Chang et al. 2003; Lee et al. 2006). TIN2 protects TRF1 from poly(ADP-ribosyl)ation by tankyrase1, without affecting tankyrase 1 automodification in vitro (Ye et al. 2004c). Tankyrase has additional non-telomeric functions on other proteins and plays a part in resolution of sister telomere association during progression through mitosis (Dynek \& Smith 2004). PARP2 has been found to target TRF2, modifying DNA binding and dimerization domains (Dantzer et al. 2004).

Telomere elongation by telomerase, in addition to the affect on telomeric proteins, is also influenced by other mechanisms. Telomerase is tightly regulated at the transcriptional level and its subcellular localization contributes to regulation of the elongation process during the cell cycle. hTR, an RNA telomerase component, ubiquitously expressed, has been found in nucleoplasmic Cajal bodies of inter-phase malignant cells and is transiently concentrated at a few telomeres during S phase (Jady et al. 2006). Wong et al. (2002) have also found that catalytically active human telomerase localization in the nucleus is dependent on the phase of the cell cycle, it resides in the nucleolus and is sequestered to the nucleoplasm at the expected time of telomere replication. hTERT nuclear export and import is regulated by 14-3-3 kinase (Seimiya et al. 2000).

Besides telomerase, there are also various alternative mechanisms of lengthening telomeres (ALT) that employ DNA recombination machinery. These mechanisms may include intertelomeric homologous recombination, t-loop recombination, rolling-circle extension and extension utilizing extra-chromosomal telomeric repeats (Neumann \& Reddel 2002). The mechanisms are still largely unknown, although an increasing number of proteins involved in the process have been described (Dunham et al. 2000; Cesare \& Griffith 2004). Because ALT is active in only $\sim 15 \%$ of tumours and tumour cell lines that have been analysed to date (Shay \& Bacchetti 1997), telomerase is the main mechanism that enables immortal cells to undergo continuous divisions. 


\section{TELOMERES AND THE DNA DAMAGE RESPONSE}

Compact protective structure of the telomere is compromised when telomere DNA has to be 'unpacked' during the process of DNA replication or telomere elongation. In that form, telomeres have many similarities to DNA breaks. Proteins involved in DNA repair and damage signalling are localized on telomeres, but they do not trigger a DNA damage response and/or cell cycle arrest (Wright et al. 1999; Zhu et al. 2000). Mre11, NBS, ATM, Ku86, DNA-PKcs, Rad50, Rad51 are proteins involved in non-homologous end joining and homologous recombination, that reside on telomeres (Hsu et al. 2000; d'Adda di Fagagna et al. 2003; Takai et al. 2003; de Lange 2005, Fig. 1). Verdun et al. (2005) have shown that activated NBS1, Mre11 and ATM are recruited to telomeres in every $\mathrm{G}_{2}$ phase of the cell cycle in telomerase-negative cells and could have a role in protection and formation of the long $\mathrm{G}$ overhang (Herbig et al. 2004; Larrivee et al. 2004); replication leaves chromosome ends blunt or with short G-tails. POT1 can be partially released leaving telomeres unprotected and accessible to modifying enzymes. Long G-tails required at both ends for t-loop formation are formed by exonuclease erosion at the $5^{\prime}$ strands (Makarov et al. 1997). TRF2 interacts with the MRN (Mre11, Rad50, NBS1) complex (Stansel et al. 2001; Karlseder et al. 2002; de Lange 2005), some specific endonucleases and exonucleases that remodel the telomere. One of them is the ERCC1/XPF endonuclease responsible for overhang processing (de Laat et al. 1998; Hoeijmakers 2001). Apollo or hSNM1B a $5^{\prime} \rightarrow 3^{\prime}$ exonuclease is another TRF2 interacting enzyme found to cooperate in telomere protection (Lenain et al. 2006; van Overbeek \& de Lange 2006). Investigations have shown that the telomeric overhang helps form a protective structure and prevents chromosome fusion (Zhu et al. 2003; Wang et al. 2004; Chai et al. 2006; Chiang et al. 2006).

In normal cells that do not express telomerase, telomere erosion and subsequent impairment leads to replicative senescence. Dysfunctional telomeres are detected as double-stranded DNA breaks that induce a DNA damage response and activation of the tumour suppressor protein p53. This is accomplished through activation of ATM kinase that phosphorylates p53 directly as well as phosphorylating the Chk2 checkpoint kinase, which promotes additional phosphorylation of p53. These modifications contribute to displacement of mdm 2 from $\mathrm{p} 53$ allowing its stabilization and activation (Kulju \& Lehman 1995; Vaziri et al. 1997; Gire et al. 2004; Artandi \& Attardi 2005). Levels of p21, the main cell cycle inhibitor, increase several times over in senescence, arresting the cell cycle in $\mathrm{G}_{1}$ phase (Noda et al. 1994; Dulic et al. 2000). Furthermore, other cyclindependent kinase inhibitors (CDKI), such as p16 that controls pRB activity, take part in this process. Long-term increase of p16 leads to chromatin modification and to final irreversibility of senescence (Dai \& Enders 2000). Under these conditions, pRb is hypophosphorylated and this contributes to heterochromatinization of DNA and stable cell cycle arrest (Narita et al. 2003).

\section{CONCLUSION}

In summary, we can say that telomeres are crucial for genome stability and cell growth control in all eukaryotes. They have a complex and dynamic structure that includes numerous specialized proteins involved in interactions with various structures in the cell. As data accumulate, we should gain greater knowledge of their function. This is highly important for attempts to develop therapies against cancer based on telomerase inhibition and subsequent telomere shortening (Corey 2002). In addition, this will lead to greater understanding of the role of these specialized structures, both in normal cell physiology and in processes such as carcinogenesis and ageing. 


\section{REFERENCES}

Artandi SE, Attardi LD (2005) Pathways connecting telomeres and p53 in senescence, apoptosis, and cancer. Biochem. Biophys. Res. Commun. 331, 881-890.

Bailey SM, Murnane JP (2006) Telomeres, chromosome instability and cancer. Nucleic. Acids Res. 34, $2408-2417$.

Bandiera A, Medic N, Akindahunsi AA, Manzini G (2005) In vitro dual binding activity of a evolutionarily related subgroup of hnRNP proteins. Mol. Cell. Biochem. 268, 121-127.

Baumann P, Podell E, Cech TR (2002) Human Pot1 (protection of telomeres) protein: cytolocalization, gene structure, and alternative splicing. Mol. Cell. Biol. 22, 8079-8087.

Bianchi A, de Lange T (1999) Ku binds telomeric DNA in vitro. J. Biol. Chem. 274, 21223-21227.

Bianchi A, Smith S, Chong L, Elias P, de Lange T (1997) TRF1 is a dimer and bends telomeric DNA. EMBO J. 16, 1785-1794.

Bilaud T, Brun C, Ancelin K, Koering CE, Laroche T, Gilson E (1997) Telomeric localization of TRF2, a novel human telobox protein. Nat. Genet. 17, 236-239.

Blasco MA (2005) Mice with bad ends: mouse models for the study of telomeres and telomerase in cancer and aging. EMBO J. 24, 1095-1103.

Bradshaw PS, Stavropoulos DJ, Meyn MS (2005) Human telomeric protein TRF2 associates with genomic double-strand breaks as an early response to DNA damage. Nat. Genet. 37, 193-197.

Broccoli D, Smogorzewska A, Chong L, de Lange T (1997) Human telomeres contain two distinct Myb-related proteins, TRF1 and TRF2. Nat. Genet. 17, 231-235.

Bryan TM, Englezou A, Gupta J, Bacchetti S, Reddel RR (1995) Telomere elongation in immortal human cells without detectable telomerase activity. EMBO J. 14, 4240-4248.

Cesare AJ, Griffith JD (2004) Telomeric DNA in ALT cells is characterized by free telomeric circles and heterogeneous t-loops. Mol. Cell. Biol. 24, 9948-9957.

Chai W, Sfeir AJ, Hoshiyama H, Shay JW, Wright WE (2006) The involvement of the Mre11/Rad50/Nbs1 complex in the generation of G-overhangs at human telomeres. EMBO Rep. 7, 225-230.

Chang W, Dynek JN, Smith S (2003) TRF1 is degraded by ubiquitin-mediated proteolysis after release from telomeres. Genes Dev. 17, 328-333.

Chiang YJ, Nguyen ML, Gurunathan S, Kaminker P, Tessarollo L, Campisi J, Hodes RJ (2006) Generation and characterization of telomere length maintenance in tankyrase 2-deficient mice. Mol. Cell. Biol. 26, 2037-2043.

Churikov D, Wei C, Price CM (2006) Vertebrate POT1 restricts G-overhang length and prevents activation of a telomeric DNA damage checkpoint but is dispensable for overhang protection. Mol. Cell. Biol. 26, 6971-6982.

Colgin L, Reddel R (2004) Telomere biology: a new player in the end zone. Curr. Biol. 14, R901-902. Review.

Corey DR (2002) Telomerase inhibition, oligonucleotides, and clinical trials. Oncogene 21, 631-637. Review.

d'Adda di Fagagna F, Reaper PM, Clay-Farrace L, Fiegler H, Carr P, Von Zglinicki T, Saretzki G, Carter NP, Jackson SP (2003) A DNA damage checkpoint response in telomere-initiated senescence. Nature 426, 194-198.

Dai CY, Enders GH (2000) p16 INK4a can initiate an autonomous senescence program. Oncogene 19, $1613-1622$.

Dantzer F, Giraud-Panis MJ, Jaco I, Ame JC, Schultz I, Blasco M, Koering CE, Gilson E, Menissier-De Murcia J, De Murcia G, Schreiber V (2004) Functional interaction between poly (ADP-ribose) polymerase 2 (PARP-2) and TRF2: PARP activity negatively regulates TRF2. Mol. Cell. Biol. 24, 1595-1607.

Dulic V, Beney GE, Frebourg G, Drullinger LF, Stein GH (2000) Uncoupling between phenotypic senescence and cell cycle arrest in aging p21-deficient fibroblasts. Mol. Cell. Biol. 20, 6741-6754.

Dunham MA, Neumann AA, Fasching CL, Reddel RR (2000) Telomere maintenance by recombination in human cells. Nat. Genet. 26, 447-450.

Dynek JN, Smith S (2004) Resolution of sister telomere association is required for progression through mitosis. Science 304, 97-100.

Ferenac M, Polancec D, Huzak M, Pereira-Smith OM, Rubelj I (2005) Early-senescing human skin fibroblasts do not demonstrate accelerated telomere shortening. J. Gerontol. A Biol. Sci. Med. Sci. 60, 820-829.

Gire V, Roux P, Wynford-Thomas D, Brondello JM, Dulic V (2004) DNA damage checkpoint kinase Chk2 triggers replicative senescence. EMBO J. 23, 2554-2563.

Gonzalo S, Jaco I, Fraga MF, Chen T, Li E, Esteller M, Blasco MA (2006) DNA methyltransferases control telomere length and telomere recombination in mammalian cells. Nat. Cell Biol. 8, 416-424.

Greider CW (1999) Telomeres do d-loop-T-loop. Cell 97, 419-422.

Greider CW, Blackburn EH (1985) Identification of a specific telomere terminal transferase activity in Tetrahymena extracts. Cell 43, 405-413.

Griffith J, Bianchi A, de Lange T (1998) TRF1 promotes parallel pairing of telomeric tracts in vitro. J. Mol. Biol. 278, $79-88$. 
Griffith JD, Comeau L, Rosenfield S, Stansel RM, Bianchi A, Moss H, de Lange T (1999) Mammalian telomeres end in a large duplex loop. Cell 97, 503-514.

Hackett JA, Greider CW (2002) Balancing instability: dual roles for telomerase and telomere dysfunction in tumorigenesis. Oncogene 21, 619-626.

Hanaoka S, Nagadoi A, Nishimura Y (2005) Comparison between TRF2 and TRF1 of their telomeric DNA-bound structures and DNA-binding activities. Protein Sci. 14, 119-130.

Hanaoka S, Nagadoi A, Yoshimura S, Aimoto S, Li B, de Lange T, Nishimura Y (2001) NMR structure of the hRap1 Myb motif reveals a canonical three-helix bundle lacking the positive surface charge typical of Myb DNA-binding domains. J. Mol. Biol. 312, 167-175.

Harley CB, Futcher AB, Greider CW (1990) Telomeres shorten during ageing of human fibroblasts. Nature 345, $458-460$.

Herbig U, Jobling WA, Chen BP, Chen DJ, Sedivy JM (2004) Telomere shortening triggers senescence of human cells through a pathway involving ATM, p53, and p21 (CIP1), but not p16 (INK4a). Mol. Cell 14, 501-513.

Hockemeyer D, Sfeir AJ, Shay JW, Wright WE, de Lange T (2005) POT1 protects telomeres from a transient DNA damage response and determines how human chromosomes end. EMBO J. 24, 2667-2678.

Hoeijmakers JH (2001) Genome maintenance mechanisms for preventing cancer. Nature 411, 366-374.

Houghtaling BR, Cuttonaro L, Chang W, Smith S (2004) A dynamic molecular link between the telomere length regulator TRF1 and the chromosome end protector TRF2. Curr. Biol. 14, 1621-1631.

Hsiao SJ, Poitras MF, Cook BD, Liu Y, Smith S (2006) Tankyrase 2 poly (ADP-ribose) polymerase domain-deleted mice exhibit growth defects but have normal telomere length and capping. Mol. Cell. Biol. 26, 2044-2054.

Hsu HL, Gilley D, Galande SA, Hande MP, Allen B, Kim SH, Li GC, Campisi J, Kohwi-Shigematsu T, Chen DJ (2000) $\mathrm{Ku}$ acts in a unique way at the mammalian telomere to prevent end joining. Genes Dev. 14, 2807-2812.

Huang S, Li B, Gray MD, Oshima J, Mian IS, Campisi J (1998) The premature ageing syndrome protein, WRN, is a $3^{\prime} \rightarrow 5^{\prime}$ exonuclease. Nat. Genet. 20, 114-116.

Jady BE, Richard P, Bertrand E, Kiss T (2006) Cell cycle-dependent recruitment of telomerase RNA and Cajal bodies to human telomeres. Mol. Biol. Cell 17, 944-954.

Kaminker P, Plachot C, Kim SH, Chung P, Crippen D, Petersen OW, Bissell MJ, Campisi J, Lelievre SA (2005) Higherorder nuclear organization in growth arrest of human mammary epithelial cells: a novel role for telomere-associated protein TIN2. J. Cell Sci. 118, 1321-1330.

Karlseder J, Smogorzewska A, de Lange T (2002) Senescence induced by altered telomere state, not telomere loss. Science 295, 2446-2449.

Karlseder J, Kachatrian L, Takai H, Mercer K, Hingorani S, Jacks T, de Lange T (2003) Targeted deletion reveals an essential function for the telomere length regulator Trf1. Mol. Cell. Biol. 18, 6533-6541.

Kelleher C, Kurth I, Lingner J (2005) Human protection of telomeres 1 (POT1) is a negative regulator of telomerase activity in vitro. Mol. Cell. Biol. 25, 808-818.

Kim SH, Kaminker P, Campisi J (1999) TIN2, a new regulator of telomere length in human cells. Nat. Genet. 23, 405-412.

Kim NW, Piatyszek MA, Prowse KR, Harley CB, West MD, Ho PL, Coviello GM, Wright WE, Weinrich SL, Shay JW (1994) Specific association of human telomerase activity with immortal cells and cancer. Science 266, 2011-2015.

Klapper W, Qian W, Schulte C, Parwaresch R (2003) DNA damage transiently increases TRF2 mRNA expression and telomerase activity. Leukemia 17, 2007-2015.

Kulju KS, Lehman JM (1995) Increased p53 protein associated with aging in human diploid fibroblasts. Exp. Cell Res. 217, 336-345.

de Laat WL, Appeldoorn E, Jaspers NG, Hoeijmakers JH (1998) DNA structural elements required for ERCC1-XPF endonuclease activity. J. Biol. Chem. 273, 7835-7842.

de Lange (2005) Shelterin: the protein complex that shapes and safeguards human telomeres. Genes Dev. 19, $2100-2110$.

de Lange T, Shiue L, Myers RM, Cox DR, Naylor SL, Killery AM, Varmus HE (1990) Structure and variability of human chromosome ends. Mol. Cell. Biol. 10, 518-527.

Larrivee M, Lebel C, Wellinger RJ (2004) The generation of proper constitutive G-tails on yeast telomeres is dependent on the MRX complex. Genes Dev. 18, 1391-1396.

Lee TH, Perrem K, Harper JW, Lu KP, Zhou XZ (2006) The F-box protein FBX4 targets PIN2/TRF1 for ubiquitin-mediated degradation and regulates telomere maintenance. J. Biol. Chem. 281, 759-768.

Lei M, Podell ER, Baumann P, Cech TR (2003) DNA self-recognition in the structure of Potl bound to telomeric singlestranded DNA. Nature 426, 198-203.

Lei M, Zaug AJ, Podell ER, Cech TR (2005) Switching human telomerase on and off with hPOT1 protein in vitro. J. Biol. Chem. 280, 20449-20456.

Lenain C, Bauwens S, Amiard S, Brunori M, Giraud-Panis M, Gilson E (2006) The Apollo 5'exonuclease functions together with TRF2 to protect telomeres from DNA repair. Curr. Biol. 16, 1303-1310. 
Li B, de Lange T (2003) Rap1 affects the length and heterogeneity of human telomeres. Mol. Biol. Cell 14, 5060-5068.

Li B, Oestreich S, de Lange T (2000) Identification of human Rap1: implications for telomere evolution. Cell 101, 471-483.

Lillard-Wetherell K, Machwe A, Langland GT, Combs KA, Behbehani GK, Schonberg SA, German J, Turchi JJ, Orren DK, Groden J (2004) Association and regulation of the BLM helicase by the telomere proteins TRF1 and TRF2. Hum. Mol. Genet. 13, 1919-1932.

Liu D, O’Connor MS, Qin J, Songyang Z (2004a) Telosome, a mammalian telomere-associated complex formed by multiple telomeric proteins. J. Biol. Chem. 279, 51338-51342.

Liu D, Safari A, O'Connor MS, Chan DW, Laegeler A, Qin J, Songyang Z (2004b) PTOP interacts with POT1 and regulates its localization to telomeres. Nat. Cell Biol. 6, 673-680.

Loayza D, De Lange T (2003) POT1 as a terminal transducer of TRF1 telomere length control. Nature 423, $1013-1018$.

Longtine MS, Wilson NM, Petracek ME, Berman J (1989) A yeast telomere binding activity binds to two related telomere sequence motifs and is indistinguishable from RAP1. Curr. Genet. 16, 225-239.

Luderus ME, van Steensel B, Chong L, Sibon OC, Cremers FF, de Lange T (1996) Structure, subnuclear distribution, and nuclear matrix association of the mammalian telomeric complex. J. Cell Biol. 135, 867-881.

Makarov VL, Hirose Y, Langmore JP (1997) Long G tails at both ends of human chromosomes suggest a C strand degradation mechanism for telomere shortening. Cell 88, 657-666.

Masutomi KYuEY, Khurts S, Ben-Porath I, Currier JL, Metz GB, Brooks MW, Kaneko S, Murakami S, Decaprio JA, Weinberg RA, Stewart SA, Hahn WC (2003) Telomerase maintains telomere structure in normal human cells. Cell 114, 241-253.

Mattern KA, Swiggers SJ, Nigg AL, Lowenberg B, Houtsmuller AB, Zijlmans JM (2004) Dynamics of protein binding to telomeres in living cells: implications for telomere structure and function. Mol. Cell. Biol. 24, 5587-5594.

Moran-Jones K, Wayman L, Kennedy DD, Reddel RR, Sara S, Snee MJ, Smith R (2005) hnRNP A2, a potential ssDNA/ RNA molecular adapter at the telomere. Nucleic. Acids Res. 33, 486-496.

Moyzis RK, Buckingham JM, Cram LS, Dani M, Deaven LL, Jones MD, Meyne J, Ratliff RL, Wu JR (1988) A highly conserved repetitive DNA sequence, (TTAGGG) n, present at the telomeres of human chromosomes. Proc. Natl. Acad. Sci. USA 85, 6622-6626.

Nakamura M, Zhou XZ, Kishi S, Kosugi I, Tsutsui Y, Lu KP (2001) A specific interaction between the telomeric protein Pin2/TRF1 and the mitotic spindle. Curr. Biol. 11, 1512-1516.

Narita M, Nunez S, Heard E, Narita M, Lin AW, Hearn SA, Spector DL, Hannon GJ, Lowe SW (2003) Rb-mediated heterochromatin formation and silencing of E2F target genes during cellular senescence. Cell 113, 703-716.

Neumann AA, Reddel RR (2002) Telomere maintenance and cancer-look, no telomerase. Nat. Rev. Cancer 2, 879-884.

Nikitina T, Woodcock CL (2004) Closed chromatin loops at the ends of chromosomes. J. Cell Biol. 166, 161-165.

Nishiyama A, Muraki K, Saito M, Ohsumi K, Kishimoto T, Ishikawa F (2006) Cell-cycle-dependent Xenopus TRF1 recruitment to telomere chromatin regulated by Polo-like kinase. EMBO J. 25, 575-584.

Noda A, Ning Y, Venable SF, Pereira-Smith OM, Smith JR (1994) Cloning of senescent cell-derived inhibitors of DNA synthesis using an expression screen. Exp. Cell Res. 21, 90-98.

O’Connor MS, Safari A, Liu D, Qin J, Songyang Z (2004) The human Rap1 protein complex and modulation of telomere length. J. Biol. Chem. 279, 28585-28591.

Ohki R, Ishikawa F (2004) Telomere-bound TRF1 and TRF2 stall the replication fork at telomeric repeats. Nucleic. Acids Res. 32, 1627-1637.

Olovnikov AM (1973) A theory of marginotomy. The incomplete copying of template margin in enzymic synthesis of polynucleotides and biological significance of the phenomenon. J. Theor. Biol. 41, 181-190.

Opresko PL, Mason PA, Podell ER, Lei M, Hickson ID, Cech TR, Bohr VA (2005) POT1 stimulates RecQ helicases WRN and BLM to unwind telomeric DNA substrates. J. Biol. Chem. 280, 32069-32080.

Opresko PL, Otterlei M, Graakjaer J, Bruheim P, Dawut L, Kolvraa S, May A, Seidman MM, Bohr VA (2004) The Werner syndrome helicase and exonuclease cooperate to resolve telomeric D loops in a manner regulated by TRF1 and TRF2. Mol. Cell 14, 763-774.

van Overbeek M, de Lange T (2006) Apollo, an Artemis-related nuclease, interacts with TRF2 and protects human telomeres in S phase. Curr. Biol. 16, 1295-1302.

Prime G, Markie D (2005) The telomere repeat binding protein Trf1 interacts with the spindle checkpoint protein Mad1 and Nek2 mitotic kinase. Cell Cycle 4, 121-124.

Riethman H, Ambrosini A, Paul S (2005) Human subtelomere structure and variation. Chromosome Res. 13, $505-515$.

Rubelj I, Vondracek Z (1999) Stochastic mechanism of cellular aging - abrupt telomere shortening as a model for stochastic nature of cellular aging. J. Theor. Biol. 197, 425-438.

Sbodio JI, Chi NW (2002) Identification of a tankyrase-binding motif shared by IRAP, TAB182, and human TRF1 but not mouse TRF1. NuMA contains this RXXPDG motif and is a novel tankyrase partner. J. Biol. Chem. 277, 31887-31892. 
Schulz VP, Zakian VA, Ogburn CE, McKay J, Jarzebowicz AA, Edland SD, Martin GM (1996) Accelerated loss of telomeric repeats may not explain accelerated replicative decline of Werner syndrome cells. Hum. Genet. 97, 750-754.

Seimiya H, Smith S (2002) The telomeric poly (ADP-ribose) polymerase, tankyrase 1, contains multiple binding sites for telomeric repeat binding factor 1 (TRF1) and a novel acceptor, 182-kDa tankyrase-binding protein (TAB182). J. Biol. Chem. 277, 14116-14126.

Seimiya H, Sawada H, Muramatsu Y, Shimizu M, Ohko K, Yamane K, Tsuruo T (2000) Involvement of 14-3-3 proteins in nuclear localization of telomerase. EMBO J. 19, 2652-2661.

Seimiya H, Muramatsu Y, Smith S, Tsuruo T (2004) Functional subdomain in the ankyrin domain of tankyrase 1 required for poly (ADP-ribosyl)ation of TRF1 and telomere elongation. Mol. Cell. Biol. 24, 1944-1955.

Sfeir AJ, Shay JW, Wright WE (2005) Fine-tuning the chromosome ends: the last base of human telomeres. Cell Cycle 4, 1467-1470.

Sharma GG, Hwang KK, Pandita RK, Gupta A, Dhar S, Parenteau J, Agarwal M, Worman HJ, Wellinger RJ, Pandita TK (2003) Human heterochromatin protein 1 isoforms HP1 (Hsalpha) and HP1 (Hsbeta) interfere with hTERT-telomere interactions and correlate with changes in cell growth and response to ionizing radiation. Mol. Cell. Biol. 23, 8363-8376.

Shay JW, Bacchetti S (1997) A survey of telomerase activity in human cancer. Eur. J. Cancer 33, 787-791.

Shelton DN, Chang E, Whittier PS, Choi D, Funk WD (1999) Microarray analysis of replicative senescence. Curr. Biol. 9, 939-945.

Shen M, Haggblom C, Vogt M, Hunter T, Lu KP (1997) Characterization and cell cycle regulation of the related human telomeric proteins Pin2 and TRF1 suggest a role in mitosis. Proc. Natl. Acad. Sci. USA 94, 13618-13623.

Smith S, de Lange T (2000) Tankyrase promotes telomere elongation in human cells. Curr. Biol. 10, $1299-1302$.

Smith S, Giriat I, Schmitt A, de Lange T (1998) Tankyrase, a poly(ADP-ribose) polymerase at human telomeres. Science 282, 1484-1487.

Smith JR, Whitney RG (1980) Intraclonal variation in proliferative potential of human diploid fibroblasts: stochastic mechanism for cellular aging. Science 207, 82-84.

Smogorzewska A, van Steensel B, Bianchi A, Oelmann S, Schaefer MR, Schnapp G, de Lange T (2000) Control of human telomere length by TRF1 and TRF2. Mol. Cell. Biol. 5, 1659-1668.

Smucker EJ, Turchi JJ (2001) TRF1 inhibits telomere C-strand DNA synthesis in vitro. Biochemistry 40, $2426-2432$.

Stansel RM, de Lange T, Griffith JD (2001) T-loop assembly in vitro involves binding of TRF2 near the 3' telomeric overhang. EMBO J. 20, 5532-5540.

van Steensel B, de Lange T (1997) Control of telomere length by the human telomeric protein TRF1. Nature 385, $740-743$.

van Steensel B, Smogorzewska A, de Lange T (1998) TRF2 protects human telomeres from end-to-end fusions. Cell 92 , 401-413.

Tahara H, Tokutake Y, Maeda S, Kataoka H, Watanabe T, Satoh M, Matsumoto T, Sugawara M, Ide T, Goto M, Furuichi Y, Sugimoto M (1997) Abnormal telomere dynamics of B-lymphoblastoid cell strains from Werner's syndrome patients transformed by Epstein-Barr virus. Oncogene 15, 1911-1920.

Takai H, Smogorzewska A, de Lange T (2003) DNA damage foci at dysfunctional telomeres. Curr. Biol. 13, 15491556.

Tanaka H, Mendonca MS, Bradshaw PS, Hoelz DJ, Malkas LH, Meyn MS, Gilley D (2005) DNA damage-induced phosphorylation of the human telomere-associated protein TRF2. Proc. Natl. Acad. Sci. USA 102, 15539-15544.

Teixeira MT, Arneric M, Sperisen P, Lingner J (2004) Telomere length homeostasis is achieved via a switch between telomerase- extendible and nonextendible states. Cell 117, 323-335.

Vaziri H, Benchimol S (1996) From telomere loss to p53 induction and activation of a DNA-damage pathway at senescence: the telomere loss/DNA damage model of cell aging. Exp. Gerontol. 31, 295-301.

Vaziri H, West MD, Allsopp RC, Davison TS, Wu YS, Arrowsmith CH, Poirier GG, Benchimol S (1997) ATM-dependent telomere loss in aging human diploid fibroblasts and DNA damage lead to the post-translational activation of $\mathrm{p} 53$ protein involving poly(ADP-ribose) polymerase. EMBO J. 16, 166018-1166033.

Veldman T, Etheridge KT, Counter CM (2004) Loss of hPot1 function leads to telomere instability and a cut-like phenotype. Curr. Biol. 14, 2264-2270.

Verdun RE, Crabbe L, Haggblom C, Karlseder J (2005) Functional human telomeres are recognized as DNA damage in $\mathrm{G}_{2}$ of the cell cycle. Mol. Cell 20, 551-561.

Wai LK (2004) Telomeres, telomerase, and tumorigenesis: a review. MedGenMed. 6, 19.

Wang RC, Smogorzevska A, de Lange T (2004) Homologous recombination generates T-loop-sized deletions at human telomeres. Cell 119, 355-368.

Wei C, Price CM (2004) Cell cycle localization, dimerization, and binding domain architecture of the telomere protein cPot1. Mol. Cell. Biol. 24, 2091-2102.

Wong JM, Kusdra L, Collins K (2002) Subnuclear shuttling of human telomerase induced by transformation and DNA damage. Nat. Cell Biol. 4, 731-736. 
Wright WE, Tesmer VM, Liao ML, Shay JW (1999) Normal human telomeres are not late replicating. Exp. Cell Res. 251, 492-499.

Wu L, Multani AS, He H, Cosme-Blanco W, Deng Y, Deng JM, Bachilo O, Pathak S, Tahara H, Bailey SM, Deng Y, Behringer RR, Chang S (2006) Pot1 deficiency initiates DNA damage checkpoint activation and aberrant homologous recombination at telomeres. Cell 126, 49-62.

Yoshimura SH, Maruyama H, Ishikawa F, Ohki R, Takeyasu K (2004) Molecular mechanisms of DNA end-loop formation by TRF2. Genes Cells $\mathbf{9}, \mathbf{2 0 5 - 2 1 8 .}$

Ye JZ, de Lange T (2004a) TIN2 is a tankyrase 1 PARP modulator in the TRF1 telomere length control complex. Nat. Genet. 36, 618-623.

Ye JZ, Donigian JR, van Overbeek M, Loayza D, Luo Y, Krutchinsky AN, Chait BT, de Lange T (2004b) TIN2 binds TRF1 and TRF2 simultaneously and stabilizes the TRF2 complex on telomeres. J. Biol. Chem. 279, 47264-47271.

Ye JZ, Hockemeyer D, Krutchinsky AN, Loayza D, Hooper SM, Chait BT, de Lange T (2004c) POT1-interacting protein PIP1: a telomere length regulator that recruits POT1 to the TIN2/TRF1 complex. Genes Dev. 18, 1649-1654.

Zhang S, Hemmerich P, Grosse F (2004) Nucleolar localization of the human telomeric repeat binding factor 2 (TRF2). J. Cell Sci. 117, 3935-3945.

Zhong Z, Shiue L, Kaplan S, de Lange T (1992) A mammalian factor that binds telomeric TTAGGG repeats in vitro. Mol. Cell. Biol. 12, 4834-4843.

Zhu X, Niedernhofer L, Kuster B, Mann M, Hoeijmakers JHJ, de Lange T (2003) ERCC1/XPF removes the 3' overhang from uncapped telomeres and represses formation of telomeric DNA-containing double minute chromosomes. Mol. Cell 12, 1489-1498.

Zhu XD, Kuster B, Mann M, Petrini JH, de Lange T (2000) Cell-cycle-regulated association of RAD50/MRE11/NBS1 with TRF2 and human telomeres. Nat. Genet. 3, 347-352. 